Neuroepidemiology 2011;37:166-167

DOI: $10.1159 / 000333347$

\section{What Is the Life Expectancy in Frontotemporal Lobar Degeneration?}

\section{Chiadi U. Onyike}

Division of Geriatric Psychiatry and Neuropsychiatry, The Johns Hopkins University, Baltimore, Md., USA

Frontotemporal lobar degeneration (FTLD) features ingravescent disintegration of temperament, judgment, conduct and communication. Impulsions, compulsions, apathy, hyperactivity, disinhibition, indifference, overeating, coarse manners and impaired awareness are typical features of the behavioral phenotype (bvFTD), whereas the aphasia phenotypes - progressive non-fluent aphasia (PNFA) and semantic dementia - are mainly characterized by progressive speech dysfluency and word agnosia. FTLD is classified on neuropathological grounds into tau, TDP43 or FUS proteinopathies.

The natural history of FTLD is still being characterized. Cohort recruitment is difficult since FTLD is relatively uncommon and phenotypically heterogeneous, so most descriptions derive from specialist clinic cohorts. Generally, FTLD natural history studies have been of two kinds: those aiming to describe the evolution of morbidity and disability, and others measuring correlations and milestones. Life expectancy, or survival, is a particularly pertinent milestone for practice and research, hence the interest in its measurement and correlates. Early survival analyses showed median survival from diagnosis of FTLD to be $7-13$ years in clinic cohorts [1-6] and 6-8 years in neuropathology series $[7,8]$. Generally, the FTLD phenotypes - behavioral, non-fluent aphasia and semantic dementia - show comparable survival times, as do corticobasal degeneration and progressive supranuclear palsy [9]. On the other hand, median survival is considerably shorter (3 years) in FTLD cases with concomitant motor neuron disease, although a subset survive for up to 5 years [10].

A recent study by Nunnemann et al. [11] adds to the now substantial body of research on life expectancy in FTLD. They measured survival in the behavioral and the aphasia phenotypes, ascertained the causes of death, and analyzed whether age at onset, sex, years of education and cognitive status at diagnosis (based on MMSE and CDR scores) were associated with survival. The sample consisted of 124 consecutive clinic referrals that were observed for (an average) 5 years after the diagnostic evaluation. Seven of the 52 subjects who were deceased had a neuropathological examination, which confirmed the FTLD diagnosis in each case.
The study showed median survival from onset in this clinical sample of FTLD cases to be 11.8 years, i.e. 10.5 years in bvFTD and 12.6 years in PNFA. Survival was not associated with age at onset, sex, number of years of education, or MMSE and CDR scores at diagnosis. The principal causes of death, which were ascertained in structured interviews of relatives, were pneumonia, choking on food, cardiovascular failure, cachexia and cancers. Sudden deaths and accidental deaths were not infrequent.

This study was hindered in its scope and depth by limited size of sample and duration of follow-up (which precluded estimation of survival in semantic dementia), and narrow selection of variables for correlation with survival. Still the findings hold value. On the basis of this study, and others that have preceded it, it is now possible to assert that life expectancy in FTLD ranges from 7 to 13 years from onset in cases that do not have motor neuron disease, and may be shorter in bvFTD than in PNFA and semantic dementia. It would appear then that survival in FTLD is comparable in many cases to that in Alzheimer's disease. This work also buttresses earlier observations $[3,12]$ that survival is not associated with the demographic characteristics of FTLD subjects, their age at illness onset, or the severity of the dementia at the time of diagnosis, and shows again that the main causes of death in FTLD are respiratory and cardiovascular disorders, and cachexia.

The stage has now become set for analyses of FTLD survival that measure correlations with clinical characteristics, such as mutism, dysphagia, falls, parkinsonism, and co-incident conditions (for example, diabetes mellitus), since there are indications in earlier work that certain clinical features may be pertinent [4, $8,13]$. By taking us in such directions, future research will eventually specify the parameters for estimations of FTLD life expectancy in individuals, in addition to providing, it is hoped, new treatment opportunities.

\section{References}

1 Pasquier F, Richard F, Lebert F: Natural history of frontotemporal dementia: comparison with Alzheimer's disease. Dement Geriatr Cogn Disord 2004;17:253-257.

-2 Le Rhun E, Richard F, Pasquier F: Natural history of primary progressive aphasia. Neurology 2005;65:887-891.

3 Roberson ED, Hesse JH, Rose KD, Slama H, Johnson JK, Yaffe K, Forman MS, Miller CA, Trojanowski JQ, Kramer JH, Miller BL: Frontotemporal dementia progresses to death faster than Alzheimer disease. Neurology 2005;65:719-725.

-4 Borroni B, Grassi M, Agosti C, Premi E, Alberici A, Paghera B, Lucchini S, Di Luca M, Perani D, Padovani A: Survival in frontotemporal lobar degeneration and related disorders: latent class predictors and brain functional correlates. Rejuvenation Res 2009;12:33-44.

\section{KARGER}

Fax +41613061234 E-Mail karger@karger.ch www.karger.com
(C) 2011 S. Karger AG, Base

0251-5350/11/0374-0166\$38.00/0 
5 Garcin B, Lillo P, Hornberger M, Piguet O, Dawson K, Nestor PJ, Hodges JR: Determinants of survival in behavioral variant frontotemporal dementia. Neurology 2009;73:1656-1661.

-6 Kang SJ, Cha KR, Seo SW, Kim EA, Cheong HK, Kim EJ, Na DL, Jeong $\mathrm{JH}$ : Survival in frontotemporal lobar degeneration in a Korean population. Alzheimer Dis Assoc Disord 2010;24:339-342.

7 Hodges J, Davies RR, Xuereb J, Kril J, Halliday G: Survival in frontotemporal dementia. Neurology 2003;61:349-354.

8 Xie S, Forman M, Farmer J, Moore P, Wang Y, Wang X, Clark C, Coslett HB, Chatterjee A, Arnold S, Rosen H, Karlawish J, van Deerlin V, Lee V, Trojanowski J, Grossman M: Factors associated with survival probability in autopsy-proven frontotemporal lobar degeneration. J Neurol Neurosurg Psychiatr 2008;79:126-129.

$\checkmark 9$ Chiu WZ, Kaat LD, Seelaar H, Rosso SM, Boon AJ, Kamphorst W, van Swieten JC: Survival in progressive supranuclear palsy and frontotemporal dementia. J Neurol Neurosurg Psychiatr 2010;81:441-445.

- $10 \mathrm{Hu}$ W, Seelaar H, Josephs K, Knopman D, Boeve B, Sorenson E, McCluskey L, Elman L, Schelhaas HJ, Parisi J, Kuesters B, Lee V, Trojanowski J, Petersen R, van Swieten J, Grossman M: Survival profiles of patients with frontotemporal dementia and motor neuron disease. Arch Neurol 2009;66:1359-1364.
11 Nunnemann S, Last D, Schuster T, Förstl H, Kurz A, Diehl-Schmid J: Survival in a German Population with Frontotemporal Lobar Degeneration. Neuroepidemiology 2011;37:160-165.

- 12 Hodges JR, Mitchell J, Dawson K, Spillantini MG, Xuereb JH, McMonagle P, Nestor PJ, Patterson K: Semantic dementia: demography, familial factors and survival in a consecutive series of 100 cases. Brain 2010;133:300-306.

13 Gräsbeck A, Englund E, Horstmann V, Passant U, Gustafson L: Predictors of mortality in frontotemporal dementia: a retrospective study of the prognostic influence of pre-diagnostic features. Int J Geriatr Psychiatry 2003;18:594-601.

Chiadi U. Onyike, MD, MHS

FTD \& Young-Onset Dementias Clinic

Division of Geriatric Psychiatry and Neuropsychiatry

The Johns Hopkins Hospital

550 N. Broadway, Suite 308, Baltimore, MD 21205 (USA)

Tel. +1 410502 2981, E-Mail conyike1@jhmi.edu 